\title{
Accessibility based automobile transport system analysis in Lithuanian regions and forecasting potential in residential areas
}

\author{
M. Jakimavicius ${ }^{1} \&$ A. Macerinskiene ${ }^{2}$ \\ ${ }^{I}$ Department of Urban Engineering, \\ Vilnius Gediminas Technical University, \\ Lithuania and Ltd. Hnit-Baltic GeoInfoServisas, Lithuania \\ ${ }^{2}$ Departament of Urban Engineering, \\ Vilnius Gediminas Technical University, Lithuania
}

\begin{abstract}
Fixing the accessibility is a standard issue of transport analysis, which can be of interest to many socioeconomic applications. In this paper we propose and discuss accessibility based Lithuanian automobile transport system analysis and a GIS (geographic information systems) calculation method for searching for potential territory according to different conditions. The main parameter is time based accessibility from the centres of Lithuanian administrative regions. Also other factors have been included such as the road network density in regions, density of local roads in regions, length of roads for 1000 inhabitants in administrative regions, length of local roads for 1000 rural inhabitants in administrative regions; GIS application computes the ratings for administrative regions. The first stage of GIS decision support system is based on two calculation methods: Topsis (Technique for Order Preference by Similarity to Ideal Solution), and SAW (Simple Additive Weighting). The second stage of the GIS application is for forecasting of potential residential areas. The major input GIS data for this application is the road and street network. Minor data include layers of buildings, engineering utilities and landscape, hydrology, culture heritage objects. Also, the application user can enter different technical parameters: driving time from the centre, possible distance from major roads, distance from concrete utility, etc. All users parameters entered would be used to generating output a GIS data potential area; which satisfies all conditions entered and protective zones of different objects.
\end{abstract}

Keywords: accessibility, GIS, automobiles transport system, road network. 


\section{Introduction}

Accessibility is considered by planners and other technicians as a key variable for territorial development and planning. The concept of accessibility incorporates not only the transport link between origin and destination and the ability for traveling by the target group, but also characteristics of the destination and the objective of the trip. However, accessibility can be measured in several different ways, such as composite measures, comparative measures, and the time-space approach; see also [1].

The accessibility concept can be applied to many spatial problems; e.g. service centre location, hospital-sitting, school closure and many others. Analysis based on the concept of accessibility is therefore ideally suited to be integrated within Geographic Information Systems (GIS). This paper expands the work in modeling accessibility fields taken by Donnay and Ledent [2] for the urban region of Liège (Belgium) and Julião [3] for Tagus Valley Region (Portugal), as well as one-stage model for Slovene municipalities [4]. In this paper, travel time (by car) and territorial allocation to the Lithuanian administrative regions have been modeled using the road network and GIS approach. Accessibility from the centre of the administrative region was taken as the main factor for automobiles transport system analysis in Lithuanian administrative regions. Also other factors have been included such as the road network density in regions, density of local roads in regions, length of roads for 1000 inhabitants in administrative regions, length of local roads for 1000 rural inhabitants in administrative regions. By comparing the georeferenced data such as road network, the territorial allocation from the administrative centres and statistical data for each administrative region of Lithuania can argue about the equity of investments distribution for each administrative region of Lithuania. Also, the GIS application (created by Hnit-Baltic Geoinfoservisas Ltd.) could be used for ranking an administrative region according its automobile transport system and potential residential area forecasting.

\section{Case in Lithuania}

Currently, Lithuania has quite a well developed road network. Lithuania is situated between several Eastern Europe counties. The road network in Lithuania has been increased since 1985-1990. After that, changes were made in order to increase pavement quality but not to expand the road network. The length of road and streets network is over $73000 \mathrm{~km}$, the length of streets is about $11500 \mathrm{~km}$.

The core of the road network consists of public roads. In Lithuania, the public roads have been classified as state roads and local roads that are administrating by municipalities. According to information from the Lithuanian Road Direction the total length of Lithuanian's public road network is about $21345 \mathrm{~km}$. The categories of public roads are as follows: motorways are state roads intended for long-distance freight traffic, and are an integral part of highway connections with neighbouring countries; expressways (fast roads) are state roads reserved for 
traffic of motor vehicles that - based on their traffic and technical elements permit fast long-distance traffic between the most important regional centres and the connection to motorways in the country and with the road system of neighbouring countries. These state roads are intended for traffic connections between the most important centres of regional importance. The last section of state roads are regional roads. This class of roads consists of class 1 that are state roads intended for traffic connections between important centres of local communities (municipalities) and traffic connections with state roads of the same or higher category. Class 2 are state roads intended for traffic between centres of local communities (municipalities) and traffic connections with state roads of the same or higher category; regional roads of class 3 are state roads intended for traffic between centres of local communities (municipalities), connections for important tourist areas (tourist roads) and border areas as well as border crossings with state roads of the same or higher category, when according to the described criteria they do not meet the conditions for a higher category. Table 1 shows the length of different category roads in Lithuania. The local roads are owned by municipalities. The length of this type of road dominates the road network of Lithuania.

Table 1: $\quad$ The length of Lithuanian roads.

\begin{tabular}{|l|c|}
\hline \multicolumn{1}{|c|}{ The road category } & Length (km) \\
\hline Highway & 1748 \\
\hline Expressway & 4873 \\
\hline Region roads & 14723 \\
\hline Local roads & about 40000 \\
\hline
\end{tabular}

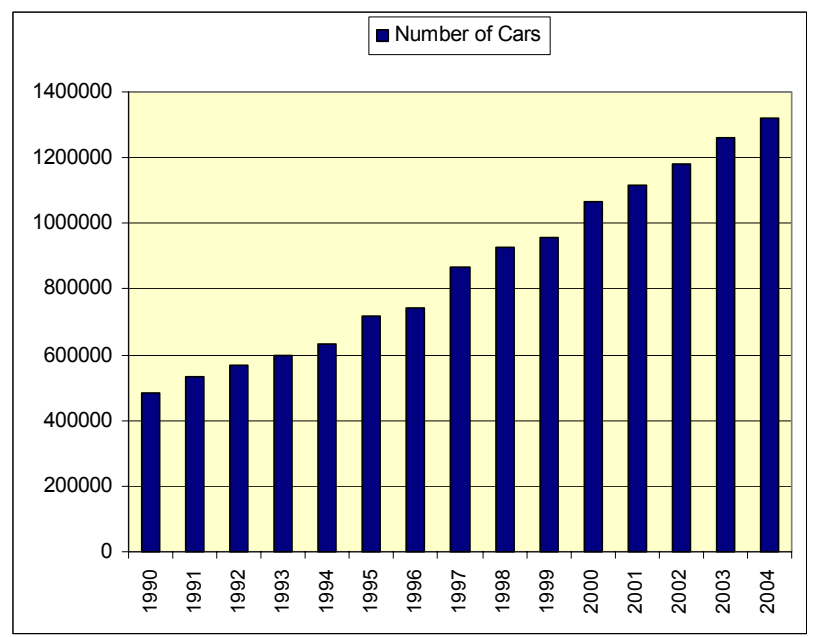

Figure 1: Number of cars in Lithuania. 
The length of the road network is not increasing but the quantity of cars is still growing; on average by about $10 \%$ per year. Currently, the number of car is 1318 000. The number of cars in Lithuania since 1990 is shown in Figure 1.

There has been a drastic rise in travel around the world from year 1960 - an average of $1820 \mathrm{~km}$ by car, railway or aircraft, to $4390 \mathrm{~km}$ in 1990 [5] - leading to substantial traffic problems in all capitals and fast growing countries.

The Growing Lithuanian economy and increasing quality of living conditions prompts population mobility, the motorization level and increasingly high transport flow on the countries streets and roads [6, 7].

Figure 2 shows the public road network in Lithuania in 2006 categorized for the application of evaluating the accessibility fields to the administrative centres, as well as administrative centres.

It was created using the GIS model, which satisfies accessibility based automobiles transport system analysis. For the input data the GIS application uses a territorial allocation from the region centre (municipality) and statistical data: road network density in regions, density of local roads in regions, length of roads for 1000 inhabitants in administrative regions, length of local roads for 1000 rural inhabitants in administrative regions.

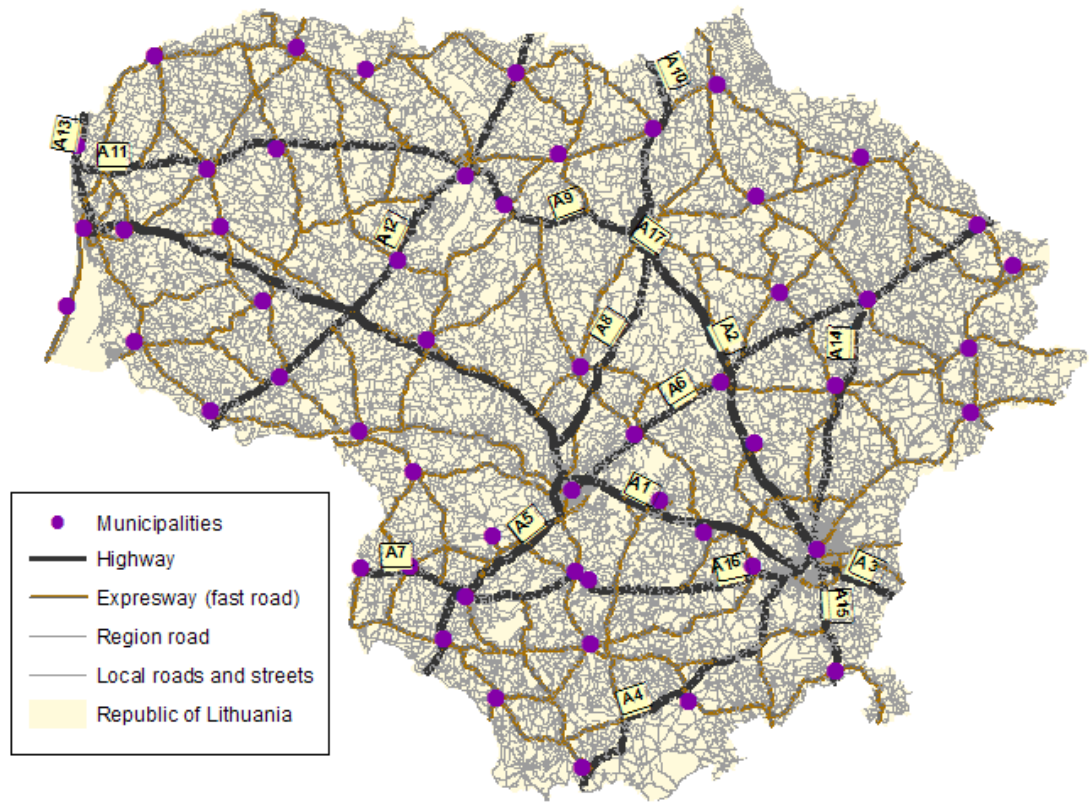

Figure 2: $\quad$ Public road network and administrative centres in Lithuania 2006.

\section{Analysis: algorithms of Lithuanian transport system analysis and forecasting potential residential areas}

A GIS based decision support system was created to perform regions ranking according to conditions of the automobile transport system. Table 2 shows 
criterions which were taken in order to perform automobile transport system ranking in the municipalities. Also the percentage importance for each criterion is given. Importance was estimated by questioning transportation system experts.

Table 2: $\quad$ Importance of criterion.

\begin{tabular}{|l|c|c|}
\hline \multicolumn{1}{|c|}{ Criterion description } & Function & $\begin{array}{c}\text { Importance } \\
(\%)\end{array}$ \\
\hline $\begin{array}{l}\text { Road network density in regions (in each } \\
\text { municipality) }\end{array}$ & maximize & 19 \\
\hline $\begin{array}{l}\text { Density of local roads in regions (in each } \\
\text { municipality) }\end{array}$ & maximize & 15 \\
\hline $\begin{array}{l}\text { Length of roads for 1000 inhabitants in } \\
\text { administrative regions (municipalities) }\end{array}$ & maximize & 18 \\
\hline $\begin{array}{l}\text { Length of local roads for 1000 rural } \\
\text { inhabitants in administrative regions } \\
\text { (municipalities) }\end{array}$ & maximize & 32 \\
\hline $\begin{array}{l}\text { Percentage coverage of territorial } \\
\text { accessibility from the administrative unit } \\
\text { going 30 minutes by car from local } \\
\text { community (municipality) }\end{array}$ & & \\
\hline
\end{tabular}

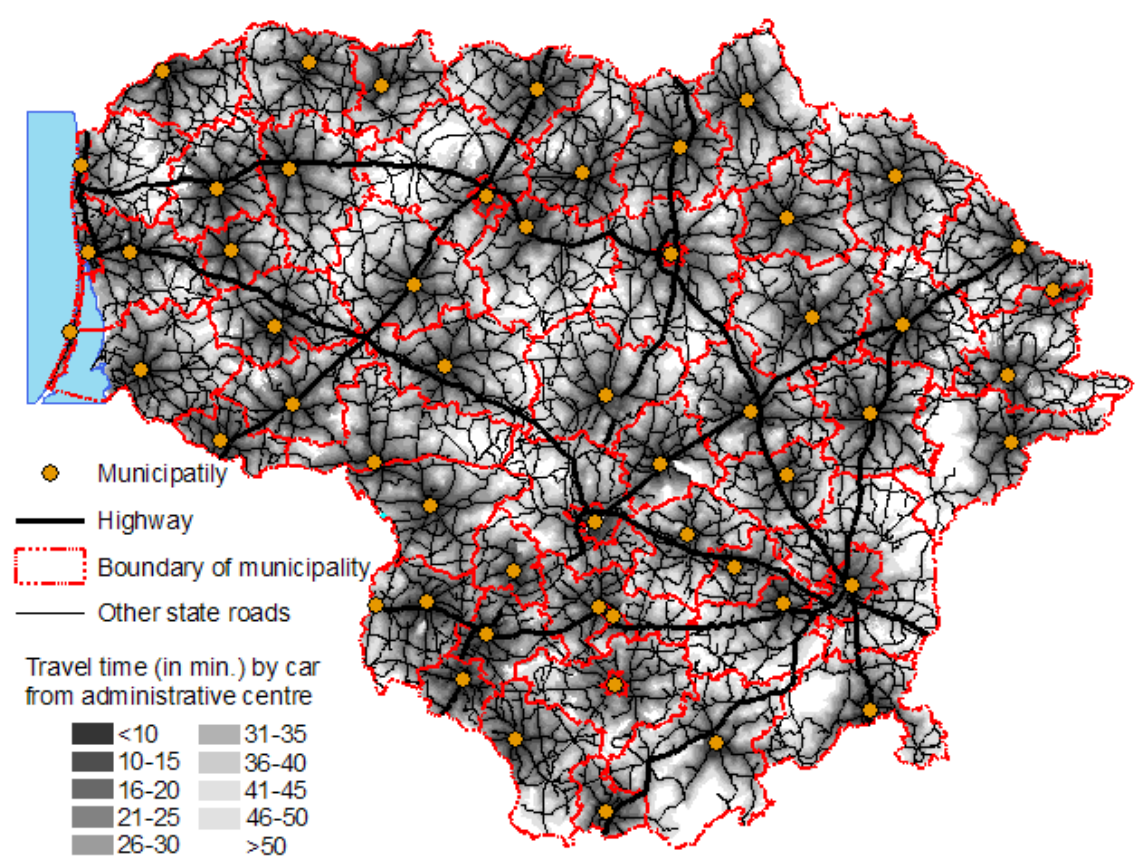

Figure 3: $\quad$ Travel time from administrative centres in Lithuania 2006. 
It was estimated that the main criterion that defines an automobiles transportation system is accessibility from the administrative centre. Figure 3 shows the travel time from administrative centres in Lithuania.

In general, accessibility was calculated by the following conditions:

- Time barriers were taken 5 minutes and period one hour;

- Travel time was taken as the optimal criteria;

- One way direction and possible turns were included in calculation model in order to perform correct analysis.

For calculating ranks that describe the automobile transport system level in each municipality calculation methods like SAW and TOPSIS were used. The GIS based application computes the ranks of automobile systems for each administrative unit. The GIS application averages results of calculation by SAW and TOPSIS.

\subsection{SAW (Simple Additive Weighting) method in GIS application}

A section of input region statistical data for the GIS application is shown in Figure 4.

\begin{tabular}{|l|l|l|l|l|l|l|l|l|l|}
\hline $\mathrm{X}_{\mathrm{ij}}$ & \multicolumn{6}{l}{ Criterions for analysis of automobiles transport system in Lithuania } \\
& $1,2 \ldots i$
\end{tabular}

Figure 4: $\quad$ Section of input region statistical data.

Input data for the calculation are criterions and their values of importance.

The criterion matrix is normalized according these conditions:

If criterion is maximized: $\quad \mathrm{X}_{\mathrm{ij}}=\frac{\mathrm{X}_{\mathrm{ij}}}{\mathrm{X}_{\mathrm{j}}^{\max }}$

If criterion is minimized: $\quad \mathrm{X}_{\mathrm{ij}}=\frac{\mathrm{X}_{\mathrm{j}}^{\mathrm{min}}}{\mathrm{X}_{\mathrm{ij}}}$

When we have normalized the matrix each criterion of concrete municipality is multiplied with its importance. Multiplied criterions are summed for each row 
(for each municipality). The highest value means the best variant for automobiles transport system in administrative region.

\subsection{TOPSIS (Technique for Order Preference by Similarity to Ideal Solution) method in GIS application}

The criterion matrix is normalized by this formula:

$$
\mathrm{X}_{\mathrm{ij}}=\frac{\mathrm{X}_{\mathrm{ij}}}{\sqrt{\sum_{\mathrm{i}=1}^{\mathrm{n}} \mathrm{X}_{\mathrm{ij}}^{2}}}
$$

The criterions matrix is multiplied with matrix of importance values $[8]: \mathrm{P}^{*}=[\mathrm{X}] \times[\mathrm{q}]$, where $\mathrm{q}-$ matrix of creations importance values. The normalized matrix is used for calculating the ideal positive $\left(\mathrm{f}_{\mathrm{j}}^{+}\right)$and negative $\left(\mathrm{f}_{\mathrm{j}}^{-}\right)$ variants. The calculation of a variant's deviation to ideal positive variant is made using:

$$
L_{i}^{+}=\sum_{j=1}^{n}\left(f_{i j}-f_{j}^{+}\right)^{2}
$$

The calculation of a variant's deviation to negative variant is given by:

$$
L_{i}^{-}=\sum_{j=1}^{n}\left(f_{i j}-f_{j}^{-}\right)^{2}
$$

The calculation of proportional variant's deviation to ideal variant $\mathrm{K}_{\mathrm{BIT}}$ :

$$
K_{B I T}=\frac{L_{i}^{-}}{L_{i}^{+}+L_{i}^{-}}
$$

The best variant of automobiles transportation system in region is with the highest $K_{B I T}$ value.

\subsection{Algorithm of potential residential area forecasting}

The GIS application for potential residential area forecasting was built according to the following conditions:

- The travel time (by car) from central part of city. Driving time was chosen like optimal criterion;

- Computed protective zones from utilities and cultural values. These zones were eliminated from potential residential area calculations. The application user can change parameters of protective zones;

- Computed water protective zones;

- Forests and hydrographical objects were eliminated from calculation;

- The application user can change the distance from a road. Output data will be the potential residential territory that satisfies the user entered parameters. 


\section{Application and results of the method}

Accessibility based automobile transport system analysis was made for Lithuanian administrative regions. Figure 5 shows the calculation results. Ranking results are calibrated computing results by TOPSIS and SAW methods:

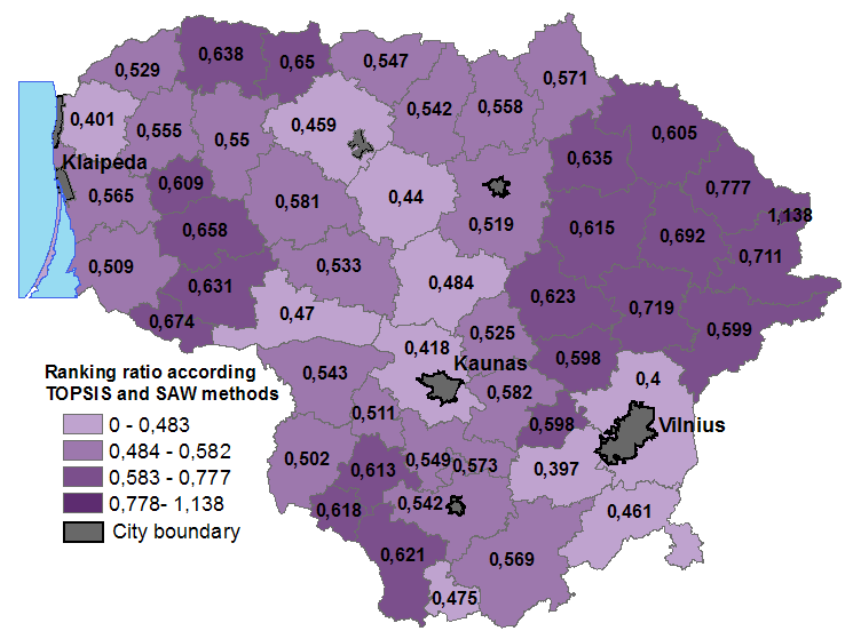

Figure 5: Automobiles transport system ranking in Lithuanian regions 2006.

Potential residential area forecasting was performed for the Vilnius region. Calculation results are shown in Figure 6.

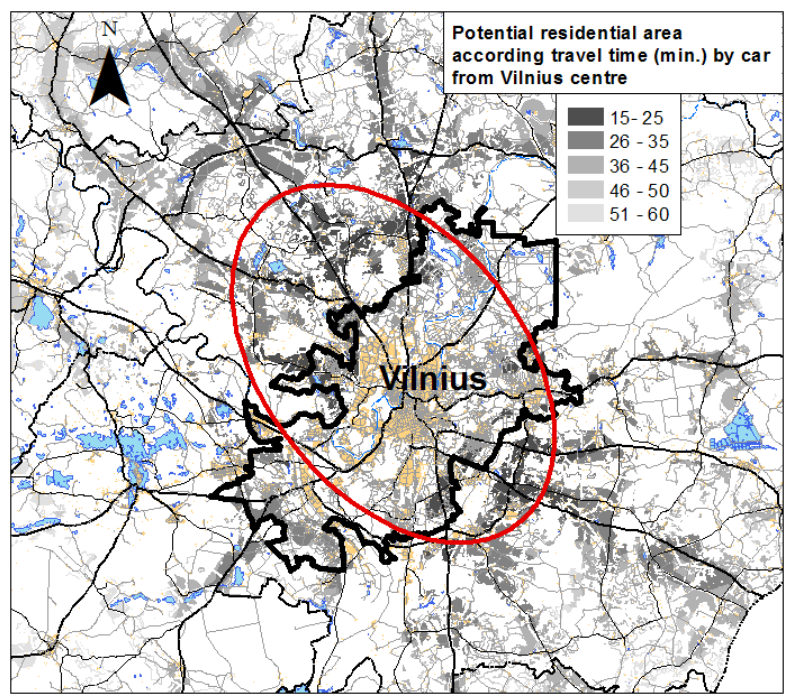

Figure 6: Potential residential area forecasting in Vilnius region 2006. 
The mechanism of potential residential area calculations eliminate such territories as protective zones from different objects, non residential territories such as forests and hydrographical objects. This calculation could be performed in concrete territories, limited by distance from roads. In the Vilnius example the maximum distance was entered as $0.5 \mathrm{~km}$.

\section{Conclusions}

The analysis results showed that the situation of automobile transport system in central and south eastern Lithuania is not as good as other Lithuanian regions. In these areas it is necessary to develop the road network and consider investments planning.

The model created could be successfully used for administrative boundary planning citizens travel time to administrative centre. A rational administrative boundary planning optimizes travel time for citizens.

The developed mechanism of the automobile transport system analysis, potential residential area forecasting and vector database may be published on the general GIS for public use and attribute information server with the help of ESRI technologies.

The database structure and calculation mechanism developed is not difficult to adapt to other states for analysis automobile transport systems and potential residential area forecasting. It is necessary to load character GIS data to the database model. The model for potential residential area forecasting could be successfully integrated with realty information systems.

\section{References}

[1] De Jong T., Ritseman van Eck, J. R. Location Profile-Based Measures as an Improvement on Accessibility Modelling in GIS. Computers, Environment and Urban Systems, 20 (3), 1997, p. 181-190.

[2] Donnay, J. P., Ledent, Ph. Modelling of Accessibility Fields. Proceedings JEC-GI ' 95 , I, 1995, p. 489-494.

[3] Julião, R. P. Measuring Accessibility Using GIS. Geo Computation Proceedings, 1999, http://www.geovista.psu.edu/sites/geocomp99/Gc99/010/gc_010.htm, date accessed: 20-04-2005.

[4] Drobne, S. Modelling accessibility fields in Slovene municipalities. Proceedings of the 7th Symposium on Operation Research in Slovenia (SOR'03). 2003, p. 89-96.

[5] Schafer A. The global demand for motorized mobility. Transportation research Vol 32, No 6, pp.1998, 455-477p.

[6] Grigonis V. Burinskienè M. Development scenarios for Vilnius public transport. Town planning and Architecture, Vol XXVII, Supplement, 2003, p.25-33. 
150 Urban Transport XII: Urban Transport and the Environment in the 21st Century

[7] Burinskiene M., Paliulis G. Consistents of car's parking in Lithuanian towns. Transport, Vol XVIII, No 4, 2003, p. 174-181.

[8] Zavadskas E.K, Simanauskas L., Kaklauskas A., Decision Support Systems in Building Engineering, Vilnius-Technika, pp. 144-150, 1999. 